\title{
PREVALENCE, DISTRIBUTION AND DETERMINANTS OF ESCHERICHIA COLI RESISTANCE TO CEFTRIAXONE IN ADULT INDOOR UTI POPULATION OF DISTRICT PESHAWAR, PAKISTAN
}

\author{
Ubed Ullah', Kiran Javed ${ }^{2}$, Muhammad Asim Khan ${ }^{3}$, Imran Ullah", Noor UI Iman' \\ Departments of ${ }^{1}$ Medicine \& ${ }^{3}$ Surgery, Khyber Teaching Hospital, Departments of ${ }^{2}$ Gynaecology \& Obstetrics \\ and ${ }^{4}$ Medicine, Lady Reading Hospital, Peshawar, Pakistan
}

\begin{abstract}
Background: Escherichia coli resistance to ceftriaxone in UTIs is an emerging health problem. Our objectives were to determine prevalence, distribution and determinants of $E$. coli resistance to ceftriaxone in adult indoor UTI population of District Peshawar, Pakistan.

Materials \& Methods: This cross-sectional study was conducted in Department of Medicine, Khyber Teaching Hospital, Peshawar, Pakistan from $1^{\text {st }}$ January 2017 to $30^{\text {th }}$ June 2017. 380 UTls cases were selected from population at risk consecutively. Sex and age groups were demographic, while presence of $E$. coli resistance to ceftriaxone was research variable. All variables were nominal. Prevalence and distribution were analyzed by count, percentage and confidence intervals for proportion for population. Hypotheses for distribution were substantiated by chi-square goodness-of-fit and of association by chi-square test of association.

Results: Out of 380 patients with UTI, 136 (35.80\%) were men, 244 (64.20\%) women, 262 (68.95\%) in age group $18-45$ years and 118 (31.05\%) in age group 46-65 years. Frequency/ prevalence of $E$. coli resistance was 287/380 (75.53\%, 95\% Cl 71.20-79.85). Out of 287 patients with $E$. coli resistance to ceftriaxone, 101 (26.58\%) were men and $186(48.95 \%)$ women, $198(52.11 \%)$ in age group 18-45 years and $89(23.42 \%)$ in age group $46-65$ years. Our prevalence of $E$. coli resistance to ceftriaxone was higher than expected $(p<.00001)$, our distribution by sex $(p<.00125)$ and age groups $(p<.00001)$ were different than expected. Presence of $E$. coli resistance to ceftriaxone was not associated to sex $(p=.669333)$ and age groups $(p=.975097)$.

Conclusion: Prevalence of $E$. coli resistance to ceftriaxone in adult UTI population of District Peshawar, Pakistan was alarmingly high $75.53 \%$. Prevalence was more in women than men and more in younger age group (18-45 years) than older age group (46-60 years) population. Overall prevalence of $E$. coli resistance to ceftriaxone was higher than expected. Distribution by sex showed higher prevalence than expected in men and lower than expected in women, and higher than expected in younger age group and lower than expected in older age group. Presence of $E$. coli resistance to ceftriaxone was not associated to sex and age groups respectively in adult UTI population of District Peshawar, Pakistan.
\end{abstract}

KEY WORDS: Urinary Tract Infections; E. coli; Ceftriaxone Resistance; Antibiotic Sensitivity; Anti-microbial Resistance; Adult; Chi-square Goodness of fit Test; Chi-square Test of Association; Peshawar; Pakistan.

Cite as: Ullah U, Javed K, Khan MA, Ullah I, Iman NU. Prevalence, distribution and determinants of Escherichia coli resistance to ceftriaxone in adult indoor UTI population of District Peshawar, Pakistan. Gomal J Med Sci 2020 Apr-Jun; 18 (2):45-53. http://doi.org/10.46903/gjms/18.02.869

\section{INTRODUCTION}

1.1 Background: Urinary tract infections (UTIs) are Corresponding Author:

Dr. Imran Ullah

Registrar, Department of Medicine

Lady Reading Hospital, Peshawar, Pakistan

E-mail: drimranullah89@gmail.com

Date Submitted: 04-01-2020

Date Revised: $\quad 10-05-2020$

Date Accepted: $\quad 01-06-2020$ common bacterial infections with significant morbidity and cost. About 150 million individuals are involved in UTI annually throughout the world, with approximate cost of more than six billion US dollars. ${ }^{1}$ Urinary tract infection is more prevalent in female than male with prevalence being highest in young adults. ${ }^{2}$ About $40-50 \%$ females get infected with UTIs once throughout their life. ${ }^{3}$ Increased women susceptibility to UTIs is due to two reasons. First, the urethral opening is near the anus and vagina and second the urethra is short which provides easy 
access of bacteria to the urinary bladder. ${ }^{4}$

Globally, Escherichia coli is the most common organism (64.5\%) causing UTI. ${ }^{5}$ Also in Pakistan E. coli was the most common uropathogen isolated from urine cultures $(73 \%)$ as compared to all others organisms (27\%). ${ }^{6}$ Two local studies showed $E$. Coli as one of the most common causative agent in UTIS $(n=77$, $68.1 \%)^{7}$ and $(\mathrm{n}=75,66.96 \%)^{8}$

Most clinicians treat UTI empirically, which may be a cause for increasing antibiotic resistance. ${ }^{9}$ Studies have showed multiple and extensive drug resistant E. coli. ${ }^{10}$ The emergence of extended-spectrum beta-lactamase has threatened the empirical use of cephalosporin and ciprofloxacin. ${ }^{11}$ Ceftriaxone is a broad spectrum parenteral third generation cephalosporin. It is empirically used in multiple types of infections. But as the bacterial resistance to the common antibacterial drugs is increasing within $E$. coli causing UTIs, its empirical use must be reviewed at times at local levels. ${ }^{12-14}$

Jamil, et al. ${ }^{8}$ from Sawabi, Khyber Pukhtunkhwa, Pakistan for the period from Sep. 2016 to April 2017 reported $100 \%$ E. coli resistance to ceftriaxone in 75 adult UTI patients. Sohail, et al. ${ }^{6}$ for the period from Dec. 2012 to Jan. 2014 and Sabir, et al. ${ }^{10}$ published in 2014 showed prevalence of $E$. coli resistance to ceftriaxone in adult UTI cases as $71 \%$ and $43.3 \%$ from samples of 244 and 321 respectively from Lahore, Pakistan. A study by Dadi, et al. ${ }^{15}$ from Ethiopia, published in 2018, reported prevalence of $E$. coli resistance to ceftriaxone in 200 adult UTI cases as $80.5 \%$. Niranjan, et al. ${ }^{16}$ from Aug 2011 to July 2012 and Prakash, et al. ${ }^{17}$ from July 2011 to Jan. 2013 have given prevalence of $E$. coli resistance to ceftriaxone in adult UTI cases as $71.4 \%$ and $53.03 \%$ from samples of 119 and 66 respectively, from India. Alam, et al. ${ }^{18 f r o m ~ D h a k a, ~ B a n g l a d e s h ~ f o r ~ t h e ~ p e r i o d ~}$ from Jan. 2016 to Dec. 2016 reported prevalence of E. coli resistance to ceftriaxone in adult UTI cases as $47.93 \%(497 * 100 / 1037=47.93 \%)$, with $12.83 \%$ in men and $35.10 \%$ in women from 497 positive cases of $E$. coli resistance out of 1037 adult UTI sample.

1.2 Research Problems, Knowledge Gaps, Research Questions\& Rationale: We don't know the prevalence of $E$. coli resistance to ceftriaxone, its distribution by sex and age groups and its association to sex and age groups in adult indoor UTI population of District Peshawar, Pakistan. Unawareness of these five pieces of information were our five research problems. Relevant data regarding these research problems could not be retrieved through online search using different search engines and databases. These were our five knowledge gaps. What would be the prevalence of $E$. coli resistance to ceftriaxone, its distribution by sex and age groups and its association to sex and age groups would be our five research questions. To find answers to these questions would be the rationale of our study.

\subsection{Research Objectives (ROs)}

RO-1: To determine the prevalence of $E$. coli resistance to ceftriaxone in adult indoor UTI population of District Peshawar, Pakistan.

RO 2-3: To determine the distribution of $E$. coli resistance to ceftriaxone by sex and age groups respectively in adult indoor UTI population of District Peshawar, Pakistan.

RO 4-5: To determine the association between E. coli resistance to ceftriaxone and sex and age groups respectively in adult indoor UTI population of District Peshawar, Pakistan.

\subsection{Research (Null) Hypotheses}

$\mathbf{H}_{01}$ : The observed and expected prevalence of $E$. coli resistance to ceftriaxone was same in adult indoor UTI population of District Peshawar, Pakistan.

$\mathbf{H}_{02}$ : The distribution of $E$. coli resistance to ceftriaxone by sex was same in adult indoor UTI population of District Peshawar, Pakistan.

$\mathbf{H}_{03}$ : The distribution of $E$. coli resistance to ceftriaxone by age groups was same in adult indoor UTI population of District Peshawar, Pakistan.

$\mathbf{H}_{04}$ : The presence of $E$. coli resistance to ceftriaxone is independent of sex in adult indoor UTI population of District Peshawar, Pakistan.

$\mathbf{H}_{05}$ : The presence of $E$. coli resistance to ceftriaxone is independent of age groups in adult indoor UTI population of District Peshawar, Pakistan.

1.5 Significance: According to above studies resistance is increasing against ceftriaxone, therefore it is necessary to have local data on $E$. coli resistance to ceftriaxone in UTIs. This will provide local and current data on this subject which will guide physicians to do urine culture and sensitivity test before using ceftriaxone or any other antibiotic as empirical therapy in UTIs. This study will encourage hospitals to make antibiotic policy for them which will avoid irrational use of antibiotics and will help in prevention of increasing antibiotic resistance.

\section{MATERIALS AND METHODS}

2.1 Study Design, Settings \& Duration: This cross-sectional study was done at the Department of Medicine, Khyber Medical College, Peshawar, Pakistan from $1^{\text {st }}$ January 2017 to $30^{\text {th }}$ June 2017. The data was collected from five medical, five surgical, three gynecology and one nephrology units of Khyber Teaching Hospital, Peshawar. Prior approval of the project was sought from the Hospital Ethical Review Committee. Patients' consent was also sought before inclusion in the study.

2.2 Population, Sample Size \& Technique and Sample Selection: District Peshawar is the most populous district of Khyber Pakhtunkhwa; a northwest province of Pakistan. Its population was 2,026,851 in 1998 Census. For 2016, it was estimat- 
ed to be around 4 million. Age group 18-65 years was assumed to contribute its $50 \%$, hence 2 million population. With overall presumed prevalence rate of $5 \%$ of UTI in this age group, ${ }^{19}$ the population with UTI will be around $100,000(5 * 2,000,000 / 100)$. Out of this population with UTI, $73 \%$ are assumed to be caused by E. coli, ${ }^{6}$ so73,000 (73*100,000/100) population with UTI caused by E. coli is our population at risk. With this much population, expected prevalence rate of $43.3 \% E$. coli resistance to ceftriaxone in this population, margin of error $4.969 \%$ and confidence interval of $95 \%$, sample size came to be 380 using online calculator Raosoft ${ }_{\circledast}{ }^{20}$

Consecutive non-probability sampling technique was used. All adults (18-65 years) indoor patients with UTI caused by $E$. coli were eligible for inclusion. All patients suffering from diabetes, HIV/AIDS or those on long term steroid therapy and patients who used antibiotics in the last 48 hours of presentation were excluded from the study.

2.3 Conduct of Procedure: Detailed history, examination and necessary investigations were done. Single sample of clean-catch mid-stream urine were taken from patients having clinical features of UTIs under strict aseptic conditions and were immediately sent to hospital laboratory for urine routine examination and inoculation on culture media for E. coli. $0.01 \mathrm{ml}$ of urine sample were put on MacConkey and blood agar media through calibrated loop and incubated aerobically for 24 hours at $37^{\circ} \mathrm{C}$. The plates showing significant growth as per Kass counts were processed further. Identification of isolated $E$. Coli was confirmed by colony characteristics, gram-staining and biochemical analysis.

E. coli growth detected was checked for ceftriaxone resistance and sensitivities. Susceptibility to ceftriaxone was determined by the minimum concentration of ceftriaxone needed to inhibit the growth of $E$. Coli on Mueller Hinton agar media by phenotypic method. This procedure was done under the supervision of one microbiologist.

2.4 Data Collection Plan: Sex (men/ women) and age groups (18-45 and 46-65 years) were demographic variables (attributes) while presence of $E$. coli resistance to ceftriaxone (yes/no) was a research variable (attributes). The data type was nominal for all the variables. The presence of $E$. coli resistance was dependent variable, while sex and age groups were independent variables respectively for test of association.

\subsection{Data Analysis Plan}

2.5.1 Descriptive Statistics and Estimation of Parameters: All the three variables were analyzed by count and percentage for the sample. The estimated parameters for the population were stated as $\mathrm{Cl}$ (confidence interval) for proportion at 95\% $\mathrm{CL}$ through normal distribution approximation by proportion $\mathrm{Cl}$ calculator. ${ }^{21}$

2.5.2 Hypotheses Testing: Observed and expected prevalence and observed and expected distribution of $E$. coli resistance to ceftriaxone by sex and age groups were substantiated by using chisquare goodness of fit test $\left.\left(\mathrm{H}_{01-3}\right)\right)^{22-24}$ The association between the presences of $E$.coli resistance to ceftriaxone and sex and age groups was substantiated by using chi-square test of association/ independence $\left(\mathrm{H}_{04-5}\right)^{22,23,25}$

\section{RESULTS}

3.1 Descriptive Statistics \& Estimation of Parameters

3.1.1 Sample Description \& Prevalence of $E$. coli resistance to ceftriaxone in adult UTI population: Out of 380 patients with UTI, $136(35.80 \%)$ were men and 244 (64.20\%) women, $262(68.95 \%)$ were in age group $18-45$ years and $118(31.05 \%)$ in age group of 46-65 years.

Out of 380 patients with UTI, $287(75.53 \%)$ had E.coli resistance to ceftriaxone, while $93(24.47 \%)$ had no resistance to ceftriaxone. Estimated prevalence in population is shown below. (Table 3.1.1)

3.1.2 Distribution of positive cases of $E$. coli resistance to ceftriaxone in adult indoor UTI population by sex and age groups: The distribution of positive cases of $E$. coli resistance to ceftriaxone by sex and age groups in adult indoor UTI population of District Peshawar are shown in Table 3.1.2. Here the frequency of $E$. coli resistance to ceftriaxone in sample and its estimated prevalence in population was more in women $48.95 \%$, than men $26.58 \%$, and more in age group $18-45$ years $52.11 \%$ than age group $46-65$ years $23.42 \%$.

Table 3.1.1: Frequency of $E$. coli resistance to ceftriaxone in sample and prevalence in adult indoor UTI population of District Peshawar, Pakistan $(n=380)$

\begin{tabular}{|l|l|c|c|c|c|}
\hline \multirow{2}{*}{ Variable } & \multirow{2}{*}{ Attributes } & \multicolumn{2}{|c|}{ Sample statistics } & \multicolumn{2}{c|}{$95 \% \mathrm{Cl}$ for proportion for population } \\
\cline { 2 - 6 } & & Count & Percentage & Lower & Upper \\
\hline $\begin{array}{l}\text { Presence of } E . \text { coli } \\
\text { resistance }\end{array}$ & Yes & 287 & $75.53 \%$ & 71.20 & 79.85 \\
\cline { 2 - 6 } & No & 93 & $24.47 \%$ & 20.15 & 28.80 \\
\hline \multicolumn{2}{|c|}{ Total } & 380 & 100 & \multicolumn{2}{c|}{ Population parameters } \\
\hline
\end{tabular}




\subsection{Hypotheses Testing}

3.2.1 Observed vs. expected prevalence of $E$. coli resistance to ceftriaxone in adult indoor UTI population $\left(\mathbf{H}_{01}\right)$ : Our observed counts for the presence of $E$. coli resistance (yes: no) were 287:93 from a sample of 380 against expected counts of 139:182 from a sample of 321 as reported by Sabir, et al. ${ }^{10}$ With different sample sizes/ denominators, comparison was not possible. Hence the expected counts and expected percentages were adjusted for a sample of 380 . The expected counts of 139:182 were replaced by 164.55:215.45. Adjusted Expected percentages came similar to expected percentages, so not changed. (Table 3.2.1.1)

Chi-square goodness-of-fit test showed p-value <alpha. $\mathrm{H}_{01}$ was declared as false and therefore rejected; showing that the observed prevalence is not similar to the expected prevalence. Simply, the prevalence of $75.53 \%$ of $E$. coli resistance to ceftriaxone in our population is significantly higher than what we were expecting from the prevalence of 43.30\% from Sabir, et al. ${ }^{10}$ (Table 3.2.1.2)

3.2.2 Observed vs. expected distribution of positive cases of $E$. coli resistance to ceftriaxone by sex in adult indoor UTI population $\left(\mathrm{H}_{02}\right)$ : Our observed distribution for men versus women was 101:186 out of 287 positive cases from a sample of 380 adult indoor UTI patients against expected counts of 133:364 from 497 positive cases of $E$. coli resistance in 1037 adult UTI population as reported by Alam, et al. ${ }^{18}$ from Dhaka, Bangladesh for the period from Jan. 2016 to Dec. 2016 $(497 * 100 / 1037=47.93 \%)$. With different sample sizes/ denominators, comparison was not possible. Hence the expected counts and expected percentages were adjusted for a sample of 380. The expected counts of 133:364 were replaced by $76.80: 210.20$ and expected percentages of $12.83 \%: 35.10 \%$ were replaced by $20.21 \%: 55.32 \%$. It is important to note

Table 3.1.2: Distribution of positive cases of $E$. coli resistance to ceftriaxone by sex and age groups in adult indoor UTI population of District Peshawar, Pakistan $(n=287 / 380)$

\begin{tabular}{|l|c|c|c|c|c|c|}
\hline \multirow{2}{*}{ Variables } & \multirow{2}{*}{ Attributes } & \multirow{2}{*}{$\begin{array}{c}\text { Sample } \\
\text { size }\end{array}$} & \multicolumn{2}{|c|}{ Sample statistics } & \multicolumn{2}{c|}{$95 \% \mathrm{Cl}$ for proportion } \\
\cline { 6 - 7 } & & Count & Percentage & Lower & Upper \\
\hline \multirow{2}{*}{ Sex } & Men & 136 & 101 & $101 * 100 / 380=26.58 \%$ & 22.14 & 31.02 \\
\cline { 5 - 7 } & Women & 244 & 186 & $186 * 100 / 380=48.95 \%$ & 43.92 & 53.97 \\
\hline \multirow{2}{*}{ Age groups } & $18-45 y e a r s$ & 262 & 198 & $198 * 100 / 380=52.11 \%$ & 47.08 & 57.13 \\
\cline { 2 - 7 } & $46-60 y e a r s$ & 118 & 89 & $89 * 100 / 380=23.42 \%$ & 19.16 & 27.68 \\
\hline & Total & 380 & 287 & $287 * 100 / 380=75.53 \%$ & 71.20 & 79.85 \\
\hline
\end{tabular}

Table 3.2.1.1: Observed, expected and adjusted expected counts and percentages for prevalence of $E$. coli resistance to ceftriaxone in adult indoor UTI population of District Peshawar, Pakistan $(n=380)$

\begin{tabular}{|l|c|c|c|c|c|c|}
\hline $\begin{array}{l}\text { Presence of } E . \\
\text { Coli resistance }\end{array}$ & $\begin{array}{c}\text { Observed } \\
\text { counts }\end{array}$ & $\begin{array}{c}\text { Observed } \\
\text { \%ages }\end{array}$ & $\begin{array}{c}\text { Expected } \\
\text { counts }\end{array}$ & $\begin{array}{c}\text { Expected } \\
\text { \%ages }\end{array}$ & $\begin{array}{c}\text { Adjusted expected } \\
\text { counts }\end{array}$ & $\begin{array}{c}\text { Adjusted expected } \\
\% \text { ages }\end{array}$ \\
\hline Yes & 287 & $75.53 \%$ & 139 & $43.30 \%$ & $139 * 380 / 321=164.55$ & $\begin{array}{c}164.55 * 100 / 380 \\
=43.30 \%\end{array}$ \\
\hline No & 93 & $24.47 \%$ & 182 & $56.70 \%$ & $182 * 380 / 321=215.45$ & $\begin{array}{c}215.45 * 100 / 380 \\
=56.70 \%\end{array}$ \\
\hline Total $(n)$ & 380 & $100 \%$ & 321 & $100 \%$ & 380 & $100 \%$ \\
\hline
\end{tabular}

Table 3.2.1.2: Observed vs. expected prevalence of $E$. coli resistance to ceftriaxone in adult indoor UTI population of District Peshawar, Pakistan $(n=380)$

\begin{tabular}{|l|c|c|c|c|c|c|c|c|c|}
\hline Variable & Attributes & $\mathrm{O}$ & $\mathrm{E}$ & $\mathrm{O}-\mathrm{E}$ & $(\mathrm{O}-\mathrm{E})^{2}$ & $(\mathrm{O}-\mathrm{E})^{2} / \mathrm{E}$ & $\chi^{2}$ & d.f. & $\mathrm{p}$-value \\
\hline \multirow{3}{*}{$\begin{array}{l}\text { Presence of } E . \\
\text { coli resistance }\end{array}$} & Yes & 287 & 165 & 122 & 14884 & 90.21 & 159.434 & 1 & $<.00001$ \\
\cline { 2 - 9 } & No & 93 & 215 & -122 & 14884 & 69.23 & $\mathrm{H}_{01}$ rejected at alpha .05 \\
\cline { 2 - 10 } & Total & 380 & 380 & \multicolumn{6}{|c|}{ Yas continuity correction applied } \\
\hline
\end{tabular}

$\mathrm{O}=$ Observed count, $\mathrm{E}=$ Expected count, $\chi^{2}=$ Chi-square statistics, d.f. $=$ degree of freedom 
that we are distributing only 287 positives (75.53\%) and not the 93 (24.47\%) negative cases out of 380 (100\%) cases. (Table 3.2.2.1)

Chi-square goodness-of-fit test showed p-value $<$ alpha. $\mathrm{H}_{02}$ was declared as false and therefore rejected, showing that the observations did not fit the statistical model of the population. In simple words, our observed prevalence of $E$. coli resistance to ceftriaxone in men $26.58 \%(101 * 100 / 380=26.58 \%)$ was statistically higher to what we expected (adjusted) for men $20.21 \%(76.80 * 100 / 380=20.21 \%)$ \& our observed prevalence of $E$. coli resistance to ceftriaxone in women $48.95 \%(186 * 100 / 380=48.95 \%)$ was lower to what we expected (adjusted) for women $55.32 \%(210.20 * 100 / 380=55.32 \%)$ from Alam, et al. ${ }^{18}$. (Table 3.2.2.2)

3.2.3 Observed vs. expected distribution of 287 positive cases of $E$. coli resistance to ceftriaxone by age groups in adult indoor UTI population $\left(\mathrm{H}_{03}\right)$ : Our observed distribution for age group 18-
45 years versus $46-65$ years was $198: 89$ out of 287 positive cases from a sample of 380 against hypothetical equal expected distribution of 143.5:143.5 (37.765\%:37.765\%) out of presumed 287 (75.53\%) positive cases from a presumed sample of 380 , as no studies could be found in different databases for distribution of $E$. coli resistance to ceftriaxone across the age groups.

Chi-square goodness-of-fit test showed p-value $<$ alpha. $\mathrm{H}_{02}$ was declared to be false and therefore rejected, showing that the observations did not fit the statistical model of the population. In simple words, our observed prevalence of $E$. coli resistance to ceftriaxone in age group $18-45$ years $52.11 \%$ was statistically higher to what we expected hypothetically for age group 18-45 years 37.765\% (percentage for expected count) \& our observed prevalence of E. coli resistance to ceftriaxone in age group 4665 years $23.42 \%$ was lower to what we expected hypothetically for age group $46-65$ years $37.765 \%$ (percentage for expected count). (Table 3.2.3)

Table 3.2.2.1:Observed, expected and adjusted expected counts and percentages for distribution of 287 positive cases of $E$. coli resistance to ceftriaxone by sex in adult indoor UTI population of District Peshawar, Pakistan $(n=380)$

\begin{tabular}{|c|c|c|c|c|c|c|}
\hline $\begin{array}{c}\text { E. coli resis- } \\
\text { tance }\end{array}$ & $\begin{array}{c}\text { Observed } \\
\text { counts }\end{array}$ & $\begin{array}{c}\text { Observed } \\
\% \text { ages }\end{array}$ & $\begin{array}{c}\text { Expected } \\
\text { counts }\end{array}$ & $\begin{array}{c}\text { Expected } \\
\text { \%ages }\end{array}$ & $\begin{array}{c}\text { Adjusted ex- } \\
\text { pected counts }\end{array}$ & Adjusted expected \% \\
\hline $\begin{array}{c}\text { Positive cases } \\
\text { in men }\end{array}$ & 101 & $\begin{array}{c}101^{*} 100 / 380 \\
=26.58 \%\end{array}$ & 133 & $\begin{array}{c}133^{*} 100 / 1037 \\
=12.83 \%\end{array}$ & $\begin{array}{c}133^{*} 287 / 497 \\
=76.80\end{array}$ & $\begin{array}{c}76.80^{*} 100 / 380 \\
=20.21 \%\end{array}$ \\
\hline $\begin{array}{c}\text { Positive cases } \\
\text { in Women }\end{array}$ & 186 & $\begin{array}{c}186 * 100 / 380 \\
=48.95 \%\end{array}$ & 364 & $\begin{array}{c}364 * 100 / 1037 \\
=35.10 \%\end{array}$ & $\begin{array}{c}364 * 287 / 497 \\
=210.20\end{array}$ & $\begin{array}{c}210.20 * 100 / 380 \\
=55.32 \%\end{array}$ \\
\hline Total positive & 287 & $\begin{array}{c}287^{*} 100 / 380 \\
=75.53 \%\end{array}$ & 497 & $\begin{array}{c}497^{*} 100 / 1037 \\
=47.93 \%\end{array}$ & $\begin{array}{c}497 * 287 / 497 \\
=287\end{array}$ & $\begin{array}{c}287 * 100 / 380 \\
=75.53 \%\end{array}$ \\
\hline
\end{tabular}

Table 3.2.2.2: Observed vs. expected distribution of 287 positive cases of $E$. coli resistance to ceftriaxone by sex in adult indoor UTI population of District Peshawar, Pakistan $(n=287 / 380)$

\begin{tabular}{|c|c|c|c|c|c|c|c|c|c|}
\hline Variable & Attributes & $\mathrm{O}$ & $\mathrm{E}$ & $\mathrm{O}-\mathrm{E}$ & $(\mathrm{O}-\mathrm{E})^{2}$ & $(\mathrm{O}-\mathrm{E})^{2} / \mathrm{E}$ & $\chi^{2}$ & d.f. & $\mathrm{p}$-value \\
\hline \multirow{3}{*}{ Sex } & Men & 101 & 76.80 & 24.20 & 585.64 & 7.63 & 10.412 & 1 & .00125 \\
\cline { 2 - 9 } & Women & 186 & 210.20 & -24.20 & 585.64 & 2.79 & $\mathrm{H}_{02}$ rejected at alpha .05 \\
\cline { 2 - 9 } & Total & 287 & 287.00 & \multicolumn{5}{|c|}{ Yates continuity correction applied } \\
\hline
\end{tabular}

$\mathrm{O}=$ Observed count, $\mathrm{E}=$ Expected count, $\chi^{2}=$ Chi-square statistics, d.f. $=$ degree of freedom

Table 3.2.3: Observed vs. expected distribution of 287 positive cases of $E$. coli resistance to ceftriaxone by age groups in adult indoor UTI population of District Peshawar, Pakistan

\begin{tabular}{|c|c|c|c|c|c|c|c|c|c|}
\hline Variable & Attributes & $\mathrm{O}$ & $\mathrm{E}$ & $\mathrm{O}-\mathrm{E}$ & $(\mathrm{O}-\mathrm{E}) 2$ & $(\mathrm{O}-\mathrm{E}) 2 / \mathrm{E}$ & $\chi^{2}$ & d.f. & $\mathrm{p}$-value \\
\hline \multirow{4}{*}{$\begin{array}{c}\text { Age } \\
\text { group }\end{array}$} & $18-45$ years & 198 & 143.5 & 54.50 & 2970.25 & 20.70 & 41.397 & 1 & $<.00001$ \\
\cline { 2 - 9 } & $46-65$ years & 89 & 143.5 & -54.50 & 2970.25 & 20.70 & $\mathrm{H}_{03}$ rejected at alpha .05 \\
\cline { 2 - 9 } & Total & 287 & 287 & \multicolumn{5}{|c|}{ Yates continuity correction applied } \\
\hline
\end{tabular}

$\mathrm{O}=$ Observed count, $\mathrm{E}=$ Expected count, $\chi^{2}=$ Chi-square statistics, d.f. $=$ degree of freedom 
Table 3.2.4: Association of presence of $E$. coli resistance to ceftriaxone to sex in adult indoor UTI population of District Peshawar, Pakistan $(n=380)$

\begin{tabular}{|c|c|c|c|c|c|c|}
\hline \multirow{2}{*}{$\begin{array}{l}\text { Variable/ Attri- } \\
\text { butes }\end{array}$} & \multicolumn{2}{|c|}{ Presence of $E$. coli résistance } & \multirow{2}{*}{ Rows Total } & \multirow{2}{*}{$x^{2}$} & \multirow{2}{*}{ d.f. } & \multirow{2}{*}{ p-value } \\
\hline & Yes & No & & & & \\
\hline Sex & $O(E)\left[X^{2}\right]$ & $O(E)\left[X^{2}\right]$ & & \multicolumn{3}{|c|}{$\begin{array}{l}\text { Chi-square test of association with } \\
\text { Yates continuity correction applied }\end{array}$} \\
\hline Men & $101(102.72)$ [0.03] & 35 (33.28) [0.09] & 136 & \multirow{2}{*}{0.1824} & \multirow{2}{*}{1} & \multirow{2}{*}{0.669333} \\
\hline Women & 186 (184.28) [0.02] & $58(59.72)$ [0.05] & 244 & & & \\
\hline Columns Total & 287 & 93 & 380 & \multicolumn{3}{|c|}{$\mathrm{H}_{04}$ accepted at alpha 0.05} \\
\hline
\end{tabular}

$\mathrm{O}=$ Observed count, $\mathrm{E}=$ Expected count, $\chi^{2}=$ Chi-square statistics, d.f. $=$ degree of freedom

Table 3.2.5: Association of presence of $E$. coli resistance to ceftriaxone to age groups in adult indoor UTI population of District Peshawar, Pakistan $(n=380)$

\begin{tabular}{|l|c|c|c|c|c|c|}
\hline \multirow{2}{*}{$\begin{array}{l}\text { Variable/ Attri- } \\
\text { butes }\end{array}$} & Presence of $E$. coli resistance & \multirow{2}{*}{ Rows Total } & $\chi^{2}$ & d.f. & p-value \\
\cline { 2 - 4 } Age groups & Yes & No & & & \multicolumn{2}{|c|}{$\begin{array}{l}\text { Chi-square test of association with } \\
\text { Yates continuity correction applied }\end{array}$} \\
\hline $18-45$ years & $198(197.88)[0.00]$ & $64(64.12)[0.00]$ & 262 & \multirow{2}{*}{0.001} & 1 & 0.975097 \\
\hline $46-65$ years & $89(89.12)[0.00]$ & $29(28.88)[0.00]$ & 118 & & \\
\hline Columns Total & 287 & 93 & 380 & \multicolumn{2}{|c|}{$\mathrm{H}_{05}$ accepted at alpha 0.05} \\
\hline
\end{tabular}

$\mathrm{O}=$ Observed count, $\mathrm{E}=$ Expected count, $\mathrm{X}^{2}=$ Chi-square statistics, $\mathrm{d} . \mathrm{f} .=$ degree of freedom

\subsubsection{Association of presence of $E$. coli resistance} to ceftriaxone to sex in adult indoor UTI population $\left(\mathbf{H}_{04}\right)$ : Presence of $E$. coli resistance to ceftriaxone being a dependent variable was cross-tabulated by sex as an independent variable. With $p$-value greater than alpha, $\mathrm{H}_{04}$ was declared as true and therefore accepted, showing that the presence of $E$. coli resistance to ceftriaxone is independent of sex i.e. there is no association between the presence of E. coli resistance to ceftriaxone and sex. (Table 3.2.4)

3.2.5 Association of presence of $E$. coli resistance to ceftriaxone to age groups in adult indoor UTI population $\left(\mathrm{H}_{05}\right)$ : Presence of $E$. coli resistance to ceftriaxone being a dependent variable was cross-tabulated by age groups as an independent variable. With $p$-value greater than alpha, $\mathrm{H}_{05}$ was declared as true and therefore accepted, showing that the presence of $E$. coli resistance to ceftriaxone is independent of age groups i.e. there is no association between the presence of $E$. coli resistance to ceftriaxone and age groups. (Table 3.2.5)

\section{DISCUSSION}

4.1 Prevalence of $E$. coli resistance to ceftriaxone in adult indoor UTI population $\left(\mathbf{H}_{01}\right)$ : The frequency of $E$. coli resistance to ceftriaxone in our sample was $75.53 \%$ with estimated prevalence in adult indoor UTI population of District Peshawar as $71.20 \%-79.85 \%$ at 95\% CL. Similar prevalence to our study was noted by Sohail, et al. ${ }^{6}$ from Lahore, Pakistan for the period from Dec. 2012 to Jan. 2014 as $71 \%$ from a sample of 244 adult cases with UTI and by Niranjan, et al. ${ }^{16}$ from Puduchery, South India for the period from August 2011 to July 2012 as $71.4 \%$ from 119 indoor cases with UTI.

Lower prevalence of $E$. coli resistance to ceftriaxone than our study was shown by Prakash, et al. ${ }^{17}$ from Meerut city, India for the period from July 2011 to January 2013 as $53.03 \%$ in 66 patients with UTI and by Sabir, et al. ${ }^{10}$ from Lahore, Pakistan published in 2014 as $43.3 \%$ in 321 adult cases with UTI.

Higher prevalence to our study was shown by Jamil, et al. ${ }^{8}$ from Sawabi, Khyber Pukhtunkhwa, Pakistan for the period from September 2016 to April 2017 as $100 \%$ from 75 patients with UTI and by Dadi, et al. ${ }^{15}$ from Addis Abeba, Ethiopia published in 2018 as $80.5 \%$ from a sample of 200 patients with UTI. Our observed prevalence of $E$. coli resistance in UTI $75.53 \%$ from a sample of 380 was significantly higher $(p=<.00001)$ than what we expected as $43.3 \%$ from a study by Sabir, et al. ${ }^{10}$ from a sample of 321 .

4.2 Distribution of 287 positive cases of $E$. coli resistance to ceftriaxone in adult indoor UTI population by $\operatorname{sex}\left(\mathbf{H}_{02}\right)$ : The prevalence of $E$. coli resistance to ceftriaxone in adult indoor UTI population was higher in women $48.95 \%(95 \% \mathrm{Cl} 43.92-53.97)$ than men $26.58 \%$ (22.14-31.02) in our population.

Similarly higher prevalence in women $35.10 \%$ $(364 * 100 / 1037=35.10)$ than men as $12.83 \%$ 
$(133 * 100 / 1037=12.83 \%)$ [total ceftriaxone resistance $=497 * 100 / 1037=47.93 \%]$ was shown by Alam, et al. ${ }^{18}$ from Dhaka, Bangladesh for the period from January 2016 to December 2016.

Our observed prevalence of E.coli resistance to ceftriaxone in adult indoor UTI population from a sample of 380 in men $26.58 \%$ was statistically higher to what we expected for men $20.21 \%$ \& our observed prevalence of $E$. coli resistance to ceftriaxone in women $48.95 \%$ was statistically lower to what we expected for women $55.32 \%$ from a study by Alam, et al. ${ }^{18}$ from Dhaka, Bangladesh (adjusted expected \%). (Table 3.2.2.2)

4.3 Distribution of 287 positive cases of $E$. coli resistance to ceftriaxone in adult indoor UTI population by age groups $\left(\mathrm{H}_{03}\right)$ : The prevalence of $E$. coli resistance to ceftriaxone in adult indoor UTI population was higher in age group 18-45 years $52.11 \%(95 \% \mathrm{Cl} 47.08-57.13)$ than in age group $46-65$ years $23.42 \%(95 \% \mathrm{Cl} 19.16-27.68)$ in our population.

Our observed prevalence of $E$. coli resistance to ceftriaxone in adult UTI population from a sample of 380 in age group of $18-45$ years $52.11 \%$ was significantly higher to what we expected for age group $18-45$ years $37.765 \%$ \& our observed prevalence of $E$. coli resistance to ceftriaxone in age group $46-65$ years $23.42 \%$ was significantly lower to what we expected for age group 46-65 years $37.765 \%$, assuming equal expected counts and percentages for $E$. coli resistance to ceftriaxone for age groups in adult UTI population, as no similar studies were found for comparison.

4.4 Association of presence of $E$. coli resistance to ceftriaxone to sex in adult indoor UTI population $\left(\mathbf{H}_{04}\right)$ :

In our study there was no association between the presence of $E$. coli resistance to ceftriaxone and sex in adult indoor UTI population of District Peshawar $\left(\mathrm{H}_{04}\right)$ (Table 3.2.4, $\left.\mathrm{p}=0.669333\right)$. No similar studies were found for comparison.

4.5 Association of presence of $E$. coli resistance to ceftriaxone to age groups in adult indoor UTI population $\left(\mathbf{H}_{05}\right)$ : In our study there was no association between the presence of $E$. coli resistance to ceftriaxone and age groups in adult indoor UTI population of District Peshawar $\left(\mathrm{H}_{05}\right)$ (Table 3.2.5, $p=0.975097)$. No similar studies were found for comparison.

\subsection{Strengths/ weaknesses of the study}

4.6.1 Marwat Logical Trajectory of Research Process: We have employed this logical flow of activities, including; identifying the research problems for our population of interest, isolating the knowledge gaps, putting problems into categorical questions, narrating them in measurable objectives and collecting probable answers for our questions from the observed answers for other similar populations (research hypotheses). Next is the verification of our hypotheses; our probable answers. It is a three steps activity, including; data collection, data analysis and data interpretation. This activity will provide us observed answers regarding our population. If any of these observed answers is similar to its relevant probable answer, we say that the hypothesis is true and hence accepted. Otherwise it is rejected. This way our objectives are met, questions are answered, knowledge gaps are filled and our research problems are solved; the ultimate justification and significance of our research process. ${ }^{26-30}$

4.6.2 Population-Sample-Population flow: Research is a never ending activity to identify and solve problems for a specified/ defined population. But many studies are started from a sample and ended with a sample. We have specified our population and then the sample is drawn. Variables of interest are identified with their attributes and data types. Data is collected by observation/ questionnaire/ interview from that sample. Data is analyzed to describe the sample (descriptive statistics), then it is inferred to the population from which it was drawn to describe that population (estimation of parameter- inferential statistics) and lastly the data from the samples is compared to tell us the differences between the populations or relationships between the variables (hypothesis testing-inferential statistics). ${ }^{26-30}$

4.6.3 Cause-n-effect analysis: The best evidence to identify determinants (causes/ risk factors) of a disease/ health related event is an experiment, which is un-ethical in humans. Then is the cohort and then is the case-control study. The minimum evidence is from cross-sectional study, which we have employed. This cannot tell which variable is cause/ exposure/ risk factor and which one is the effect/ disease. The only evidence it can give is that the two variables are seen together more often than by chance.

\section{CONCLUSIONS \& RECOMMENDATIONS}

1. Prevalence of $E$. coli resistance to ceftriaxone in adult UTI population of District Peshawar, Pakistan was alarmingly high $75.53 \%$.

2. The prevalence was more in women than men and more in younger age group (18-45 years) than older age group (46-60 years) population.

3. Our overall prevalence of $E$. coli resistance to ceftriaxone was higher than expected.

4. The distribution by sex showed higher prevalence than expected in men and lower than expected in women, and higher than expected in younger age group and lower than expected

in older age group.

5. The presence of $E$. coli resistance to ceftriaxone was not associated to sex and age groups respectively in adult UTI population of District Peshawar, Pakistan. 
A trend of decrease in bacterial susceptibility to ceftriaxone indicates that the clinicians should be careful in rational use of antimicrobial agents for their patients. They should go for individual culture and sensitivity testing, and where it is not practicable, should use these conservatively relying on susceptibility data in local context.

Acknowledgement: Dr. Muhammad Marwat from Gomal Medical College, D.I.Khan is highly acknowledged to grant us permission to use his "Marwat Logical Trajectory of Research Process" and for population \& sample calculation and for critical review of the manuscript.

\section{REFERENCES}

1. Gonzalez CM, Schaeffer AJ. Treatment of urinary tract infection: what's old, what's new, and what works. World J Urol1999 Dec 1; 17(6):372-82. https://doi.org/10.1007/s003450050163

2. Khan G, Ahmad S, Anwar S. Frequency of uropathogens in different gender and age groups. Gomal J Med Sci 2013 Jan-Jun; 11(1): 20-3.

3. Momtaz H, Karimian A, Madani M, Safarpoor Dehkordi F, Ranjbar R, Sarshar M, et al. Uropathogenic Escherichia coli in Iran: Serogroup distributions, virulence factors and antimicrobial resistance properties. Ann Clin Microbiol Antimicrob 2013 Apr 29; 12:8. https://doi. org/10.1186/1476-0711-12-8

4. Humayun $T$, Iqbal $A$. The culture and sensitivity pattern of urinary tract infections in females of reproductive age group. Ann Pak Inst Med Sci 2012;8(1):19-22.

5. Linhares I, Raposo T, Rodrigues A, Almeida A. Frequency and antimicrobial resistance patterns of bacteria implicated in community urinary tract infections: a ten-year surveillance study (20002009). BMC Infect Dis 2013 Jan 18; 13:19. https:// doi.org/10.1186/1471-2334-13-19

6. Sohail M, Khurshid M, Saleem HG, Javed $H$, Khan AA. Characteristics and antibiotic resistance of urinary tract pathogens isolated from Punjab, Pakistan. Jundishapur J Microbiol 2015 Jul;8 (7):e19272. https://doi.org/10.5812/ jjm.19272v2

7. Shahzad KA, Ullah F, Muhammad K, Khatoon F, Qazi M, Ahmed I. Multiple drug resistance patterns in urinary tract infection patients in District Peshawar, Khyber Pukhtunkhwa (KPK) Pakistan. J Inf Mol Biol 2013; 1(4):67-70.

8. Jamil J, Haroon M, Sultan A, Khan MA, Gul N, Kalsoom. Prevalence, antibiotic sensitivity and phenotypic screening of ESBL/MBL producer E. coli strains isolated from urine; District Swabi, KPK, Pakistan. J Pak Med Assoc 2018 Nov 1; 68(11):1704-7.

9. Dash M, Padhi S, Mohanty I, Panda P, Parida B. Antimicrobial resistance in pathogens causing urinary tract infections in a rural community of Odisha, India. J Family Community Med 2013 Jan; 20(1):
20-6. https://doi.org/10.4103/2230-8229.108180

10. Sabir S, Anjum AA, ljaz T, Ali MA, Khan MR, Nawaz M. Isolation and antibiotic susceptibility of $E$. coli from urinary tract infections in a tertiary care hospital. Pak J Med Sci 2014 Mar; 30(2):389-92. https://doi.org/10.12669/pjms.302.4289

11. Pondei K, Oladapo O, Kunle-Olowu OE. Anti-microbial susceptibility pattern of micro-organisms associated with urinary tract infections in a tertiary health institution in the Niger Delta Region of Nigeria. African J Microbiol Res 2012 Jun $21 ; 6(23): 4976-82$. https://doi.org/10.5897/ AJMR12.086

12. Picozzi SCM, Casellato S, Rossini M, Paola G, Tejada M, Costa E, et al. Extended-spectrum betalactamase-positive E. Coli causing complicated upper urinary tract infection: Urologist should act in time. Urology Annals 2014 Apr; 6(2):107-12. https://doi.org/10.4103/0974-7796.130536

13. Dehbanipour R, Rastaghi S, Sedighi M, Maleki N, Faghri J. High prevalence of multidrug-resistance uropathogenic Escherichia coli strains, Isfahan, Iran. J Nat Sc Biol Med 2016; 7:22-6. https://doi. org/10.4103/0976-9668.175020

14. Ahmad W, Jamshed F, Ahmad W. Frequency of Escherichia coli in patients with community acquired urinary tract infection and their resistance pattern against some commonly used anti bacterials. J Ayub Med Coll Abbottabad 2015 Jun 20; 27(2):333-7.

15. Dadi BR, Abebe T, Zhang L, Mihret A, Abebe W, Amogne W. Drug resistance and plasmid profile of uropathogenic Escherichia coli among urinary tract infection patients in Addis Abeba. J Infect Dev Ctries 2018 Aug 31; 12(08):608-15. https:// doi.org/10.3855/jidc.9916

16. Niranjan V, Malini A. Antimicrobial resistance pattern in Escherichia coli causing urinary tract infection among inpatients. Indian J Med Res 2014 Jun; 139(6): 945-8.

17. Prakash D, Saxena RS. Distribution and antimicrobial susceptibility pattern of bacterial pathogens causing urinary tract infection in urban community of Meerut City, India. ISRN Microbiol 2013 Oct 29; 2013: 749629. https://doi. org/10.1155/2013/749629

18. Alam MJ, Mousumi SJ, Rana R, Islam MS, Akter MS, Juliana FM, et al. Ceftriaxone resistance patterns of uropathogens isolated from urinary tract infection patients in selected areas of Dhaka city, Bangladesh. IOSR J Nursing Health Sci 2017;6(5):28-34.

19. Goddard J, Turner AN. Kidney and urinary tract disease. In: Walker BR, Colledge NR, Ralston $\mathrm{SH}$, Penman ID, editors. Davidson's Principles and Practice of Medicine. 22nded. New Delhi: Elsevier; 2014. p. 461-523.

20. Raosoft ${ }^{\circledR}$ sample size calculator [internet]. Seattle, WA, USA: Raosoft Inc.; 2004. [accessed 2018 Aug 13]. Available at: http://www. raosoft. com/samplesize.html 
21. Statistics Kingdom. Proportion confidence interval calculator [internet]. Statistics Kingdom; Melbourne, Australia 2007. [accessed 2018 May 27]. Available at: http://www.statskingdom. com/41_proportion_confidence_interval.html

22. Zar JH. Biostatistical Analysis. 5th ed. New York: Prentice-Hall, Inc.

23. Daniel WW. Biostatistics: A Foundation for Analysis in the Health Sciences. 7th ed. Singapore: John Wily; 2005

24. Social Science Statistics. Statistical Tests Calculators [Internet]. [accessed 2017 Oct 12].. Available from: https://www.socscistatistics.com/tests/ goodnessoffit/default2.aspx

25. Social Science Statistics. Statistical Tests Calculators [Internet]. [accessed 2017 Oct 12]. Available from: https://www.socscistatistics.com/tests/ chisquare2/default2.aspx

26. Ghori MR, Khan H, Marwat M. Distribution of non-malignant hematological disorders by sex, age groups and type of disease based on bone marrow aspiration in population of Khyber $\mathrm{Pa}$ khtunkhwa, Pakistan. Gomal J Med Sci 2019 Apr-Jun; 17 (2): 29-36. https://doi.org/10.46903/ gjms/17.02.1926
27. Butt M, Rehman MU, Khan AR, Abrar A. Frequency of triple-vessel coronary artery disease in adult type 2 diabetics versus non-diabetics in coronary artery disease population of Islamabad, Pakistan. Gomal J Med Sci 2019 Apr-Jun; 17(4).37-41. https://doi.org/10.46903/gjms/17.02.2029

28. Ain N, Khan S, Marwat M, Khan N, Ahmad I, Ramzan F, et al. Frequency, distribution and determinants of hypertension in adult stroke population of D.I.Khan Division, Pakistan. Gomal J Med Sci 2019 Jul-Sep; 17 (3):81-9. https://doi. org/10.46903/gjms/17.03.2076

29. Akhtar A, Ali SM, Naqi SA, Aziz T, Shinwari W, Shah SFH. Efficacy of acetic acid versus ciprofloxacin ear drops in achieving dry ears in chronic suppurative otitis media in adult population of Islamabad, Pakistan: a non-randomized control trial. Gomal J Med Sci 2019 Jul-Sep; 17 (3): 90-94. https://doi.org/10.46903/gjms/17.03.2007

30. Marwat M, Ahmad I, Ashiq F, Ali S, Zamir S, Rehman MU, et al. Frequency, distribution and determinants of diabetes mellitus in adult acute coronary syndrome population of D.I.Khan Division, Pakistan. Gomal J Med Sci 2019 OctDec; 17 (4):131-43. https://doi.org/10.46903/ gjms/17.04.2106

\section{CONFLICT OF INTEREST \\ Authors declare no conflict of interest. GRANT SUPPORT AND FINANCIAL DISCLOSURE None declared.}

\section{AUTHORS' CONTRIBUTION}

The following authors have made substantial contributions to the manuscript as under: Conception or Design: UU, NUI Acquisition, Analysis or Interpretation of Data: UU, KJ, MAK, IU, NUI Manuscript Writing \& Approval: UU, KJ, MAK, IU, NUI

All the authors agree to be accountable for all aspects of the work in ensuring that questions related to the accuracy or integrity of any part of the work are appropriately investigated and resolved. 